\title{
Nova Scotia confirms swine flu case contracted within Canada
}

First published at www.cmaj.ca on Apr. 30.

$\Gamma$ he first case of human-to-human transmission of $\mathrm{A}(\mathrm{H} 1 \mathrm{~N} 1)$ swine flu within Canada has been confirmed by Nova Scotia health authorities. A student at King's-Edgehill School in Windsor, Nova Scotia contracted the flu from another student who'd caught swine flu while in Mexico, the source of the outbreak that has prompted the World Health Organization to declare a Phase 5 pandemic alert.

The student is demonstrating only "mild symptoms" and is recovering nicely, says Patricia Jreige, spokesperson for Nova Scotia Health Promotion and Protection.

Jreige adds that the case came as no surprise to Nova Scotia authorities. "It was expected to spread. We've been noting that from the beginning. It's taking it's usual course."

No change in provincial procedures is required as a result of the case, Jreige says. "We've been following the protocols. It's business as usual."

King's-Edgehill Marketing and Communications Director Susan McLeod says no details surrounding the case can be disclosed because of student privacy concerns.

King's-Edgehill Headmaster Joseph Seagram posted a letter on the school's website Apr. 30 confirming that 4 students had tested positive for swine flu. Two have been released from isolation, while the other 2 remain in isolation. The school is awaiting the results from another 8 swabs being tested at the $\mathrm{Na}$ tional Microbiology Laboratory of Canada in Winnipeg, Manitoba.
The swabs are also expected to test positive, meaning 12 students at the school will have contracted swine flu. The 4 students who originally acquired the virus during a trip in Mexico are all now fully recovered.

With Alberta and Nova Scotia reporting 8 new cases of swine flu on Apr. 30, there were 27 confirmed cases across Canada. WHO declaration of a pandemic is conditional upon community level outbreaks "in at least one other country in a different WHO region." Phase 5 is "characterized by human-to-human spread of the virus into at least 2 countries in one WHO region." — Wayne Kondro, CMAJ

DOI:10.1503/cmaj.090834 